\title{
Integrin $\beta 4$ promotes invasion and anoikis resistance of papillary thyroid carcinoma and is consistently overexpressed in lymphovascular tumor thrombus
}

\author{
Jian $\mathrm{Li}^{1,2}$, Minghua Luo ${ }^{1}$, Huiting Ou ${ }^{3}$, Xiaoling Liu ${ }^{4}$, Xueling Kang ${ }^{5}$, and Weihua Yin ${ }^{1 凶}$ \\ 1. Department of Pathology, Peking University Shenzhen Hospital, Shenzhen, Guangdong Province, 518036, China. \\ 2. State Key Laboratory of Chemical Oncogenomics, Peking University Shenzhen Graduate School, Shenzhen, Guangdong Province, 518055, China \\ 3. Department of Endocrinology, Shenzhen Second People's Hospital, Guangdong Province, 518035, China. \\ 4. Department of Thyroid and Breast Surgery, Peking University Shenzhen Hospital, Shenzhen, Guangdong Province, 518036, China. \\ 5. Department of Oncology, Peking University Shenzhen Hospital, Shenzhen, Guangdong Province, 518036, China. \\ $\triangle$ Corresponding author: Weihua Yin; weihuayin_sz@sina.com, Tel: +86-755-8392-3333
}

(C) The author(s). This is an open access article distributed under the terms of the Creative Commons Attribution License (https://creativecommons.org/licenses/by/4.0/). See http://ivyspring.com/terms for full terms and conditions.

Received: 2019.04.28; Accepted: 2019.08.29; Published: 2019.10.21

\begin{abstract}
Although the majority of papillary thyroid cancers (PTC) are indolent, a subset of PTCs behaves aggressively due to extensive invasion and distant metastasis. Integrin $\beta 4$, a member of the integrin family, has been shown to enhance the progression in some malignancies; however, its role in PTC remains unclear. Here, we demonstrated that $\beta 4$ overexpression was associated with extrathyroid extension, lymph node metastasis, high TNM stage, and poor overall survival based on The Cancer Genome Atlas cohort. Immunohistochemistry showed that $\beta 4$ expression was significantly upregulated in the tumors with infiltrating growth pattern, as well as those with positive lymphovascular invasion. Moreover, $\beta 4$ was invariably overexpressed in the lymphovascular tumor thrombi, which has not been reported before. After shRNA-induced knockdown of $\beta 4$ in vitro, the migration, invasion and scratch repair ability of the tumor cells were significantly reduced. Furthermore, $\beta 4$ reduction decreased anchorage-independent growth and increased anoikis. The bioinformatics analysis revealed that approximately 70 pathways were significantly dysregulated in the high $\beta 4$ expression group. The MAPK pathway and propanoate metabolism were located in the network center of those pathways. Taken together, our results suggest that $\beta 4$ could promote the tumor's aggressiveness by enhancing invasion and antagonizing anoikis. The upregulated expression of $\beta 4$ in the tumor thrombi is intrinsically linked to its role in strengthening the anoikis resistance.
\end{abstract}

Key words: integrin $\beta 4$, papillary thyroid carcinoma, anoikis, lymphovascular tumor thrombus

\section{Introduction}

Invasion and metastasis are the main causes of death in malignancies [1-5]. Papillary thyroid carcinoma (PTC) is generally considered a low-grade malignancy with an overall 5-year survival rate of nearly $95 \%$. However, approximately $5-20 \%$ of PTCs show recurrence, and $10-15 \%$ present distant metastases, which exhibit enhanced aggressiveness [6-8]. Despite the use of comprehensive treatments, including surgical resection, radioactive ${ }^{131} \mathrm{I}$, external radiation, and thyroid-stimulating hormone (TSH) inhibition, the mortality of highly aggressive PTC has not been significantly improved [9]. Therefore, it is imperative to elucidate the potential mechanisms associated with highly invasive PTC and search for more effective therapeutic targets.

Integrin $\beta 4$ is a member of the integrin family and forms a heterodimer with a6 subunit, which acts as an adhesion receptor for laminins in the extracellular matrix (ECM) [10]. Under physiological conditions, $\beta 4$ is mainly expressed on the basement membrane in epithelial cells and connects with the intracellular intermediate filaments and extracellular laminins to form hemidesmosomes. However, in the tumor microenvironment, $\beta 4$ is mobilized from 
hemidesmosomes and moves to the filamentous actin protrusions, where it facilitates the migration of tumor cells $[11,12]$. In addition, $\beta 4$ can function as a signaling transducer by activating pathways, e.g., PI3-K, MAPK, NF-KB, and thus promote tumor aggressiveness in some malignancies, such as squamous cell carcinoma, breast cancer, and gastric cancer [13-16]. Thus $\beta 4$ has been considered an attractive therapeutic target and a small molecular compound was recently developed to antagonize $\beta 4$-overexpressed tumors [17-19].

Serini et al. first revealed the neoexpression of $\beta 4$ by neoplastic cells in PTC in 1996 [20]. Since then, only one report further addressed the role of $\beta 4$ in PTC and demonstrated the positive correlation between $\beta 4$ expression and gross lymph node metastasis [21]. To the best of our knowledge, no systematic evaluations have been conducted to illustrate the regulating function of $\beta 4$ on the aggressiveness of PTC. To this end, we first investigated the relationship between $\beta 4$ expression and clinicopathological features of PTC based on The Cancer Genome Atlas (TCGA) database; then the correlation of $\beta 4$ expression with tumor's growth pattern, histological variant, BRAFV600E mutation and lymphovascular invasion (LVI) based on immunohistochemical analysis; and finally the effects of $\beta 4$ on the tumor cells' invasion, anchorage-independent growth, and anoikis based on shRNA-induced cell models in vitro. In addition, the metabolic and transductional pathways associated with high $\beta 4$ expression were explored through in silico analysis.

\section{Materials and Methods}

\section{TCGA data analysis}

The clinical information and mRNA-seq data, including 507 thyroid carcinoma samples and 58 noncancerous thyroid tissues, were downloaded from TCGA database (https://portal.gdc.cancer.gov/) on February 25, 2018. All mRNA levels of the samples were normalized and measured using the IlluminaHiSeqRNA-seq V2 platform. Of the 507 cases of thyroid carcinoma, 505 were PTC, 1 was follicular thyroid carcinoma, and 1 was poorly differentiated thyroid carcinoma. There were 5 PTC samples without $\beta 4 \mathrm{mRNA}$ expression data. Therefore, the number of PTC cases included in the study was 500 . The median $\beta 4$ mRNA level was set as the cut off value to stratify 500 cases of PTC into $\beta 4$ mRNA high (>median value) and low ( $\leq$ median value) expression groups. TNM classification of thyroid carcinoma provided by TCGA database was based on the sixth and seventh edition of the Cancer Staging Manual issued by American Joint Committee on Cancer (AJCC).

\section{Histopathologic category}

PTC with a well circumscribed growth pattern (WC-PTC) was defined as that with an expansive growth pattern without a capsule or limited by a capsule with no or minimal invasion [22-24]. WC-PTCs that were completely or almost entirely composed of follicles were considered as non-invasive follicular thyroid neoplasm with papillary-like nuclear features (NIFTP) [25, 26] and excluded from the research. Moreover, the presence of solid growth pattern, tumor necrosis, multifocal growth or increased mitotic activity ( $>5$ per 10 high power fields) were also excluded from the analysis [22]. PTC with a poorly circumscribed growth pattern (PC-PTC) was those that with an infiltrative growth pattern or with a widely invaded capsule [22, 24].

A total of 1008 consecutive cases of PTC resected at Peking University Shenzhen Hospital, Shenzhen, China, from January 1, 2016 to December 31, 2017 were enrolled. Two senior pathologists (Jian Li and Weihua Yin) reevaluated and confirmed the growth patterns and histological variants. The classification of histological variants was based on the 4th edition of the WHO classification of tumors of endocrine organs [27]. Of the enrolled cases, there were 40 cases of WC-PTC, all of which were the classic variant of PTC, and 968 cases of PC-PTC, including 824 cases of the classic variant, 70 cases of the follicular variant, 31 cases of the oncocytic variant, 19 cases of the tall cell variant, 7 cases of the diffuse sclerosing variant, 12 cases of the solid variant, and 1 case of the cribriform-morular variant, and 4 cases of NIFTP. Twenty-five cases from the WC-PTC group, and 60 cases from the PC-PTC group, including 20 cases of classic variant, 20 cases of follicular variant and 20 cases of oncocytic variant were randomly selected. In addition, all of the following cases from the PC-PTC group, including 19 cases of tall cell variant, 7 cases of diffuse sclerosing variant and 12 cases of solid variant, were enrolled. Thus, the total number of cases studied was 123 . The ratio of females to males was 84 to 39 , and the mean patient age at surgery was $36.63 \pm 12.02$ years (mean $\pm S D)$. The clinicopathological data of the 123 patients were shown in Supplementary Table S1. The protocol and acquisition of tissue specimens in this study were reviewed and approved by the Ethics Committee of Peking University Shenzhen Hospital, and informed consent was provided by the patients involved.

\section{Immunohistochemistry}

Four-micrometer-thick sections were processed by immunohistochemistry using an automated immunostainer (Ventana Benchmark ${ }^{\circledR} \quad$ XT autostainer, Ventana Medical Systems, Inc., Tucson, 
AZ, USA). The sections were deparaffinized and rehydrated, and the endogenous peroxidase activity was blocked. Then, antigen retrieval was performed in citrate buffer for $24 \mathrm{~min}$ at $100^{\circ} \mathrm{C}$. Next, the sections were incubated with a rabbit monoclonal anti-integrin $\beta 4$ antibody (1:400 dilution, Cat. ab182120, Abcam, Cambridge, UK) for $24 \mathrm{~min}$ at $37^{\circ} \mathrm{C}$. After the sections were washed with PBS, they were treated with an ultraView Universal HRP multimer (Ventana Medical Systems), which contained a cocktail of HRP-labeled goat anti-rabbit and anti-mouse secondary antibodies, for $8 \mathrm{~min}$ at $37^{\circ} \mathrm{C}$, visualized with 3, 3'-diaminobenzidine chromogen (ultraView Universal DAB Detection kit, Ventana Medical Systems) and finally counterstained with hematoxylin. Negative controls were performed by omitting the primary antibody. The peripheral nerve inside the slide was used as an internal positive control.

\section{Evaluation on the $\boldsymbol{\beta} 4$ immunostaining score}

Evaluation on $\beta 4$ immunohistochemical staining was based on the methods introduced by Masugi et al. [28] and was modified as described below. Because the peripheral nerves exhibited consistent strong positive $\beta 4$ staining, it was used as the internal positive control. The tumor cells of PTC demonstrated two distinct staining patterns: Pattern 1, equal or stronger diffuse cytoplasmic staining compared with that of peripheral nerves and Pattern 2, predominant basal membranous staining with weak or no cytoplasmic staining. Tumor cells with staining pattern 1 were considered $\beta 4$-overexpressing cells. The percentage of $\beta 4$-overexpressing cells per total tumor cells in each slide was assessed and scored as $1,2,3$, or 4 if the percentage was $<25 \%$ (one quarter), $25 \%$ to $<33.33 \%$ (one third), $33.33 \%$ to $<50 \%$ (one half), or $\geq 50 \%$, respectively. The score was carefully evaluated by two senior pathologists (Jian $\mathrm{Li}$ and Weihua Yin). The histogram of the overexpression score was presented in Supplementary Figure S1 and the median score was 2. Tumors with scores of $>2$ were considered to have high $\beta 4$ expression, and those with scores of $\leq 2$ were defined to have low $\beta 4$ expression.

\section{BRAFV600E mutation detection by polymerase chain reaction (PCR) amplification}

DNA was extracted from paraffin-embedded sections using the QIAamp DNA Mini Kit (Qiagen, Hilden, Germany) according to the manufacturer's instructions. The upstream and downstream primers targeting the BRAF exon 15 containing codon 600 were $5^{\prime}$ - TCATAATGCTTGCTCTGATAGGA-3' and 5'-GGCCAAAAATTTAATCAGTGGA-3' as described previously [29]. The primers were synthesized by Sangon Biotech Co., Ltd. (Shanghai, China). The
$\mathrm{A}_{260} / \mathrm{A}_{280}$ values were between 1.8 and 2.0 in all DNA samples. A $25 \mu \mathrm{l}$ reaction system was established for the PCR process, which included purified genomic DNA $(0.1 \mu \mathrm{g} / \mu \mathrm{l}) 2 \mu \mathrm{l}$, forward primer $(10 \mu \mathrm{M}) 0.5 \mu \mathrm{l}$, reverse primer $(10 \mu \mathrm{M}) 0.5 \mu \mathrm{l}, 10 \times$ buffer (Promega, Madison, WI, USA) $2.5 \mu \mathrm{l}, \mathrm{MgCl}_{2}(25 \mathrm{mM}) 1.5 \mu \mathrm{l}$, dNTP $(10 \mathrm{mM}) 1 \mu \mathrm{l}$, Taq polymerase (Promega) $0.3 \mu \mathrm{l}(5 \mathrm{U} / \mu \mathrm{l})$, and the distilled water $16.7 \mu l$. The amplification protocol comprised 35 cycles: predenaturation at $95^{\circ} \mathrm{C}$ for $5 \mathrm{~min}$; denaturation at $95^{\circ} \mathrm{C}$ for $30 \mathrm{sec}$; annealing at $55^{\circ} \mathrm{C}$ for $50 \mathrm{sec}$; extension at $72^{\circ} \mathrm{C}$ for $1 \mathrm{~min}$; and a final extension at $72^{\circ} \mathrm{C}$ for $7 \mathrm{~min}$. PCR products were electrophoresed on $2.5 \%$ agarose gels, purified and subsequently sent to Geneski Biotechnologies Inc. (Shanghai, China) for sequencing. The mutation status of the sequence was determined by comparison with the genomic DNA of BRAF.

\section{Cell lines}

The thyroid cancer cell line $\mathrm{K} 1$ and the human primary thyroid epithelial cell line Nthy-ori 3-1 were obtained from the European Collection of Authenticated Cell Culture (ECACC, Salisbury, UK). The thyroid cancer cell lines BCPAP and TPC1 were obtained from the Cell Bank of the Chinese Academy of Science (Shanghai, China) and EK-biosciencs Co., Ltd. (Shanghai, China), respectively. All cells were cultured under standard conditions $\left(37^{\circ} \mathrm{C}\right.$ and $5 \%$ $\mathrm{CO}_{2}$ ). $\mathrm{K} 1$ and Nthy-ori 3-1 cells were grown in RPMI 1640 (Gibco, Carlsbad, CA, USA) supplemented with $10 \%$ FBS (Gibco) and $2 \mathrm{mM}$ L-glutamine (Gibco). The BCPAP cells were cultured in RPMI1640 supplemented with 10\% FBS. TPC1 cells were maintained in DMEM/F12 (Gibco) supplemented with $10 \%$ FBS.

\section{Knockdown of $\beta 4$ expression by lentiviral short hairpin RNA (shRNA)}

The recombinant lentivirus containing small interfering RNA targeting $\beta 4$ (shRNA- $\beta 4$ ) and a scramble negative control (shRNA-scramble) were commercially prepared by Genechem Co., Ltd. (Shanghai, China) [30]. The targeting shRNA sequence for $\beta 4$ was 5'-GAGGGTGTCATCACCAT TGAA--3', as reported previously [31]. The scramble shRNA sequence was 5'-TTCTCCGAACGTGTCA CGT-3' [32]. A lentivirus transfer vector (GV248) was ligated with the shRNA sequence. Lentiviral was packaged by transfection of $293 \mathrm{~T}$ cells with the recombinant GV248, and 2 packaging vectors: pHelper 1.0 and pHelper 2.0. Three days after transfection, the lentivirus particles were collected, filtered, and concentrated by ultracentrifugation at $4^{\circ} \mathrm{C}$ from the supernatant of $293 \mathrm{~T}$ cells. $\mathrm{K} 1$ cells were seeded in 12-well plates $\left(3 \times 10^{4}\right.$ cells/well) and when 
grown to approximately $20 \%$ confluence, the cells were transfected with the lentiviral-shRNA at a final concentration of $5 \mathrm{pfu} /$ cell for $16 \mathrm{~h}$. Subsequently, the cells were changed to routine culture media and cultured continuously for $56 \mathrm{~h}$. The green fluorescence of GFP in the infected K1 cells was observed by inverted fluorescence microscopy. If the fluorescence rate reached over $80 \%$, the cells were collected for $\beta 4$ knockdown efficiency examination and used for downstream experiments.

\section{Western blotting analysis}

$\beta 4$ protein expression was determined by Western blot analyses. The indicated cells were rinsed twice with ice-cold PBS and lysed in RIPA buffer containing protease inhibitors (Beyotime, Shanghai, China), and protein concentrations were measured by a BCA Protein Assay Kit (Beyotime). Twenty micrograms of protein from each sample was separated by $8 \%$ SDS-polyacrylamide gel electrophoresis (SDS-PAGE) and transferred onto polyvinylidene fluoride (PVDF) membranes (Thermo Fisher Scientific, Waltham, MA, USA). Membranes were incubated with a rabbit monoclonal anti-integrin $\beta 4$ antibody (1:500 dilution, Cat.ab182120, Abcam) at $4^{\circ} \mathrm{C}$ overnight. The membranes were then washed three times with TBST buffer $(0.05 \mathrm{~mol} / \mathrm{L}$ Tris, 0.15 $\mathrm{mol} / \mathrm{L} \mathrm{NaCl}$, and $0.05 \%$ Tween 20 ) and incubated with horseradish peroxidase conjugated goat anti-rabbit secondary antibody (1:2000 dilution, Cat.sc-2004, Santa Cruz, Dallas, TX, USA) for $1 \mathrm{~h}$ at room temperature. After three washes in TBST buffer, antibody binding was visualized using a Pierce ${ }^{\mathrm{TM}} \mathrm{ECL}$ Western Blotting Substrate according to the manufacturer's protocol (Thermo Fisher Scientific). Experiments were repeated three times.

\section{Transwell migration assay}

Cell migration was performed in transwell chambers (Corning Inc., Corning, NY, USA). K1 cells transfected with shRNA- $\beta 4$ or shRNA-scramble $\left(1 \times 10^{5}\right.$ cells/well $)$ were seeded in the upper chambers with serum-free medium. The lower chambers contained $10 \%$ FBS medium as an attractant. After incubation at $37^{\circ} \mathrm{C}$ for $48 \mathrm{~h}$, the migrated cells on the lower membrane surface were fixed in methanol and stained with crystal violet. The number of migrating cells in 9 randomly selected fields was counted under 200× microscope fields, and the means for each chamber were determined. Experiments were repeated three times.

\section{Transwell invasion assay}

Cell invasion was performed in Corning ${ }^{\circledR}$ BioCoat ${ }^{\mathrm{TM}}$ Matrigel ${ }^{\circledR}$ Invasion Chamber (Corning Inc.). K1 cells transfected with shRNA- $\beta 4$ or
shRNA-scramble $\left(1 \times 10^{5}\right.$ cells/well $)$ were seeded in the upper chambers with serum-free medium, and the lower chambers contained 10\% FBS medium as an attractant. After $72 \mathrm{~h}$, the invasive cells on the lower membrane surface were fixed in methanol and stained with crystal violet. The number of invasive cells in 9 randomly selected fields was counted under 200x microscope fields, and the means were determined. Experiments were repeated three times.

\section{Wound healing assay}

K1 cells transfected with shRNA- $\beta 4$ and shRNA-scramble were seeded into a 96 Wounding Replicator (VP Scientific, San Diego, CA, USA) at a density of $5 \times 10^{4}$ cells/well with medium containing $10 \%$ FBS and grown until the monolayer adherent cell confluence was $>90 \%$. A wound was scraped across the cell monolayer. Culture plates were washed with serum-free medium and incubated with medium containing $0.5 \%$ FBS. Photomicrographs were taken at the zero time point, $24 \mathrm{~h}$, and $48 \mathrm{~h}$ to measure the ratio of the migrating distance relative to the initial wound distance. Experiments were repeated three times.

\section{Soft agar assay and anoikis analysis}

K1 cells transfected with shRNA- $\beta 4$ and shRNA-scramble were suspended in RPMI 1640 with $10 \%$ FBS containing $0.3 \%$ low melt agarose (Promega) and overlaid $\left(3 \times 10^{3}\right.$ cells/well) on a solid $0.6 \%$ agar layer in six-well plates. The cultures were maintained for 14 days, and RPMI 1640 medium with 10\% FBS was added during the process to keep the upper agarose moist. Then, the colonies containing 50 cells or more were quantified by counting 5 randomly selected fields per well under $\times 40$ microscope fields.

Anoikis was assessed by measuring cytoplasmic DNA fragmentation using a Cellular DNA Fragmentation ELISA Kit (Roche Diagnostics, Mannheim, Germany) following the manufacturer's protocol. Briefly, K1 cells transfected with shRNA- $\beta 4$ or shRNA-scramble $\left(1 \times 10^{5}\right.$ cells/well $)$ were seeded on an ultra-low attachment 24-well plate (Corning, Inc.) and incubated with $5^{\prime}$-bromo-2'-deoxy-uridine (BrdU) labeling solution for $12 \mathrm{~h}$ at $37^{\circ} \mathrm{C}$. The BrdU-labeled cells were then suspended in BrdU-free culture medium and lysed to extract apoptotic DNA fragments from the cytoplasm. The supernatant lysate $(100 \mu 1)$ was transferred to 96-well, flat-bottom plate, which was pre-coated with anti-DNA antibody, incubated overnight at $4^{\circ} \mathrm{C}$, and then denatured the DNA by microwave irradiation for $5 \mathrm{~min}$ on $500 \mathrm{~W}$ power. Anti-BrdU antibody conjugated with peroxidase $(100 \mu l)$ was added and incubated overnight at $4^{\circ} \mathrm{C}$. Finally, 3, 3', 5, 5'-tetramethylbenzidine (TMB) $(100 \mu l)$ was used as the substrate 
solution and the absorbance of the samples was measured at $450 \mathrm{~nm}$ using a microplate reader (HBS-1096A, DeTie Laboratory Equipment Co., Ltd., Nanjing, China). The rate of apoptosis is presented as the fold change of the absorbance of shRNA- $\beta 4$ to shRNA-scramble-treated cells. Experiments were repeated three times.

\section{Gene set enrichment analysis (GSEA) and pathway relation network (Path-Net) analysis}

Five hundred cases of PTC in TCGA cohort were stratified into high and low $\beta 4$ expression groups by the median value of $\beta 4$ mRNA expression level. GSEA (ver.3.0, http://www.broad.mit.edu/gsea/) was applied to identify gene sets enriched in the $\beta 4$ high expression group. Gene sets were compiled from the Kyoto Encyclopedia of Genes and Genomes (KEGG). An enrichment score (ES) was calculated for gene sets, and then, a random permutation analysis was performed to estimate the significance level of ES and adjust for multiple hypothesis testing. We performed 1000 permutations and selected a false discovery rate (FDR) threshold $<0.05$ to designate statistically significant enrichment.

Path-Net analysis was further employed to reveal potential interactions among the significant pathways established from the above GSEA. Path-Net reflected the interaction features of the dysregulated pathways directly and systemically [33, 34]. This network was built based on the interactions among the pathways in KEGG database and analyzed using Cytoscape software (ver.3.2, https://cytoscape.org/). We chose 45 significant pathways, including 25 upregulated pathways and 20 downregulated pathways, for Path-Net analysis and used "Degree" to evaluate the pathway interactions.

\section{Statistical analysis}

All data were analyzed using SPSS Ver.22.0 (IBM Corporation, Armonk, NY, USA) and GraphPad Prism Ver.7.0 (GraphPad Software, Inc., La Jolla, CA, USA). Student's two-tailed $t$-test was used to compare the $\beta 4$ mRNA expression levels between PTC and normal thyroid tissues in TCGA cohort. Correlation analysis between $\beta 4$ expression levels and clinicopathologic characteristics was performed using a chi-square test (Pearson test and continuity correction test). The impacts of the clinicopathological factors on overall survival (OS) were evaluated using univariate Cox regression analyses. Multivariate Cox regression analyses were performed to determine independent prognostic factors based on the factors that were significant in the univariate Cox regression analyses. The Kaplan-Meier method was used to delineate survival curves. In vitro experimental data were compared between two groups using Student's two-tailed $t$-tests, and comparisons between three sets of data were analyzed using one-way ANOVA. The data were shown as the mean \pm SEM and were obtained from three independent experiments. $P<0.05$ was considered statistically significant.

\section{Results}

\section{Relationship between $\beta 4$ mRNA expression and clinicopathological features of PTC}

Using the data from TCGA cohort, we observed a significant increase in $\beta 4$ mRNA expression in PTC tissue $(n=500)$ compared to normal thyroid tissue $(\mathrm{n}=58)(P<0.001)$ (Figure 1). We categorized the 500 cases of PTC into low $\beta 4$ expression $(n=249)$ and high $\beta 4$ expression $(n=251)$ groups according to the median value of $\beta 4$. Table 1 showed that high $\beta 4$ expression was significantly associated with extrathyroid extension $(P=0.044)$, lymph node metastasis $(P<0.001)$, high T stage $(P=0.01)$, and TNM stage $(P=0.001)$. No statistical correlation was found with age, gender, lymphocytic thyroiditis or distant metastasis.

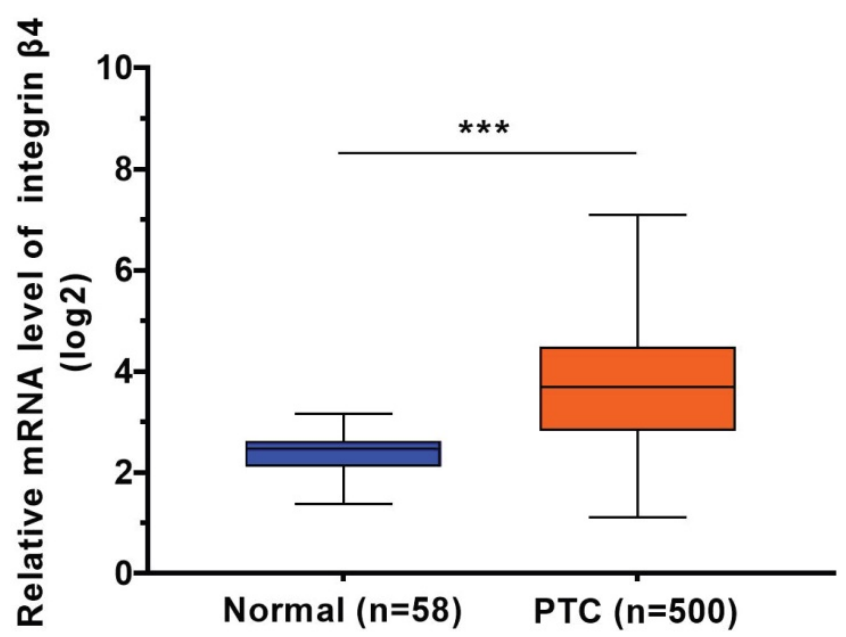

Figure 1. The relative mRNA expression level of integrin $\beta 4$ in TCGA database, including 500 cases of papillary thyroid carcinoma (PTC) samples and 58 cases of normal thyroid samples. $\beta 4$ mRNA expression was significantly upregulated in PTC. *a*k $P<0.001$ versus normal thyroid tissue.

We found no significant difference in OS between the low and high $\beta 4$ expression groups if the median $\beta 4$ expression level was set as cut-off value (data not shown). However, if the 85th percentile of $\beta 4$ expression level was set as the threshold, the OS of PTC patients was significantly different $(P=0.029)$ between the two groups (Supplementary Figure S2). Patient age, extrathyroid extension, distant metastasis, high T stage, and high TNM stage were also significant factors associated with decreased OS. However, the Cox multivariate regression indicated that only extrathyroid extension and distant metastasis were independent predictors related to the 
unfavorable OS (Supplementary Table S2). These results suggested that overexpression of $\beta$ was correlated with a low survival rate of PTC at the cut-off level of the 85th percentile; however, it was not an independent predictor.

Table 1. The relationship between integrin $\beta 4$ mRNA expression and clinicopathological features in the TCGA cohort

\begin{tabular}{|c|c|c|c|c|}
\hline \multirow[t]{2}{*}{ Characteristic } & \multirow[t]{2}{*}{ Total, $n(\%)$} & \multicolumn{2}{|c|}{$\beta 4$ mRNA expression $*, n(\%)$} & \multirow[t]{2}{*}{$P$ value } \\
\hline & & Low & High & \\
\hline Sex & & & & 0.963 \\
\hline Female & $365(73)$ & $182(73)$ & $183(73)$ & \\
\hline Male & 135 (27) & $67(27)$ & $68(27)$ & \\
\hline Age (years) & & & & 0.175 \\
\hline$<45$ & $226(45)$ & $105(42)$ & $121(48)$ & \\
\hline$\geq 45$ & $274(54)$ & $144(58)$ & $130(52)$ & \\
\hline Extrathyroid extensiont $\$$ & & & & 0.044 \\
\hline None/minimal & $463(96)$ & $231(98)$ & $232(94)$ & \\
\hline Moderate/Advanced & $19(4)$ & $5(2)$ & $14(6)$ & \\
\hline Lymphocytic thyroiditis $\$$ & & & & 0.111 \\
\hline None & $370(84)$ & $173(81)$ & $197(87)$ & \\
\hline Present & $70(16)$ & $40(19)$ & $30(13)$ & \\
\hline T stage s $^{\S}$ & & & & 0.010 \\
\hline $\mathrm{T} 1 / \mathrm{T} 2$ & $306(61)$ & $167(67)$ & $139(56)$ & \\
\hline $\mathrm{T} 3 / \mathrm{T} 4$ & $192(39)$ & $82(33)$ & $110(44)$ & \\
\hline N stage $\S$ & & & & $<0.001$ \\
\hline No & $227(51)$ & $138(64)$ & $89(38)$ & \\
\hline N1 & $223(49)$ & $78(36)$ & $145(62)$ & \\
\hline M stage§ & & & & 0.995 \\
\hline M0 & $464(98)$ & $233(98)$ & $231(98)$ & \\
\hline M1 & $9(2)$ & $4(2)$ & $5(2)$ & \\
\hline TNM stage§ & & & & 0.001 \\
\hline $\mathrm{I} / \mathrm{II}$ & $332(67)$ & $183(74)$ & $149(60)$ & \\
\hline III/IV & 166(33) & $65(26)$ & 101(40) & \\
\hline
\end{tabular}

*The cases were stratified into high and low $\beta 4$ expression group by the cut-off value set on median expression level of $\beta 4$.

†Extrathyroid extension is defined according to the 6th edition of TNM classification of thyroid carcinoma issued by American Joint Committee on Cancer (AJCC). Minimal extrathyroid extension refers to invasion to sternohyoid muscle or perithyroid soft tissue, and moderate/advanced extension refers to invasion to subcutaneous soft tissue, larynx, trachea, esophagus, or recurrent laryngeal nerve. $\S$ In the database of TCGA, there were 18 cases without the information on extrathyroid extension, 60 cases without the information on lymphocytic thyroiditis, 2 cases without the information on T stage, 50 cases without the information on $\mathrm{N}$ stage, 27 cases without the information on $\mathrm{M}$ stage, and 2 cases without the information on TNM stage.

\section{Relationship between $\beta 4$ protein expression and histological features of PTC}

We further evaluated the expression of $\beta 4$ protein in 123 PTCs by immunohistochemistry. The tumor cells of PTC showed positive immunostaining of $\beta 4$, while $\beta 4$ was negatively expressed or very faintly stained in the cytoplasm of thyroid follicular cells in normal thyroid tissue (Figure 2A, 2B). Two staining pattern of $\beta 4$ was observed in PTC. One was characterized by the strong cytoplasmic staining in tumor cells (pattern 1) (Figure 2C), and another was characterized by the predominant basal membranous staining with weak or no cytoplasmic staining in tumor cells (pattern 2) (Figure 2D). The tumor cells with staining pattern 1 were considered as $\beta 4$-overexpressing cells. Thus, the PTC cases were categorized as low and high $\beta 4$ expression group based on the staining scores of tumor cells with staining pattern 1 (see Materials and Methods).

We noted that the $\beta 4$ expression was frequently upregulated at the invasive frontier in PTC (Figure $2 \mathrm{~A})$, which prompted us to explore the $\beta 4$ expression difference between WC-PTC and PC-PTC. The results revealed that $\beta 4$ was significantly highly expressed in the PC-PTC group, in comparison with the WC-PTC group $(P=0.015)$ (Table 2 and Figure 3 ). Previous studies have shown that compared with WC-PTC, PC-PTC exhibited an increased risk in lymph node metastasis and capsule invasion [23, 24], while the mechanism has not been fully illustrated. The increased $\beta 4$ expression might be a potential contributor for the enhanced aggressiveness of PC-PTC.

Table 2. The relationship between the expression level of integrin $\beta 4$ and histological features in papillary thyroid carcinoma

\begin{tabular}{|c|c|c|c|c|}
\hline \multirow[t]{2}{*}{ Characteristic } & \multirow[t]{2}{*}{ Total, $n(\%)$} & \multicolumn{2}{|c|}{$\beta 4$ protein expression, $n(\%)$} & \multirow[t]{2}{*}{$P$ value } \\
\hline & & Low & High & \\
\hline Growth pattern of PTC & & & & 0.015 \\
\hline Well circumscribed & $25(20)$ & $20(28)$ & $5(10)$ & \\
\hline Poorly circumscribed & $98(80)$ & $52(72)$ & $46(90)$ & \\
\hline $\begin{array}{l}\text { Histologic variant of poorly } \\
\text { circumscribed PTC }\end{array}$ & & & & 0.55 \\
\hline Classical & $20(20)$ & $10(19)$ & $10(22)$ & \\
\hline Follicular & $20(20)$ & $14(27)$ & $6(13)$ & \\
\hline Oncocytic & $20(20)$ & $11(21)$ & $9(20)$ & \\
\hline Tall cell & 19(19) & $8(15)$ & $11(24)$ & \\
\hline Diffuse sclerosing & $7(8)$ & $4(8)$ & $3(7)$ & \\
\hline Solid & $12(13)$ & $5(10)$ & $7(14)$ & \\
\hline BRAFV600E mutation & & & & 0.195 \\
\hline Positive & $59(48)$ & $31(43)$ & $28(55)$ & \\
\hline Negative & $64(52)$ & $41(57)$ & $23(45)$ & \\
\hline $\begin{array}{l}\text { Lymphovascular tumor } \\
\text { thrombus }\end{array}$ & & & & $<0.001$ \\
\hline Present & $30(24)$ & $9(13)$ & $21(41)$ & \\
\hline Absent & $93(76)$ & $63(87)$ & $30(59)$ & \\
\hline
\end{tabular}

Next, we evaluated the differential expression of $\beta 4$ in 20 cases of the classic variant, 20 cases of the follicular variant, 20 cases of the oncocytic variant, 19 cases of the tall cell variant, 7 cases of the diffuse sclerosing variant and 12 cases of the solid variant of PTC. The results showed that there was no significant difference in $\beta 4$ expression among these histological variants $(P=0.55) \quad($ Table 2). Additionally, the BRAFV600E mutation is thought to be associated with the high invasiveness of PTC, although there are still conflicting views $[35,36]$. Our results found no correlation between $\beta 4$ expression and the BRAFV600E mutation $(P=0.195)$ (Table 2$)$.

LVI has been shown to be a high-risk factor for persistent and recurrent events in PTC [37, 38]. We found that the detection rate of LVI was significantly higher in the high $\beta 4$ expression group than the low $\beta 4$ expression group $(P<0.001)$ (Table 2$)$. It is suggested that increased expression of $\beta 4$ may promote the occurrence of LVI. Particularly, we noted 
that in the 30 PTCs with LVI, all tumor thrombi exhibited high expression of $\beta 4$ (Figure 4, B, D and E). Regarding their corresponding tumor parenchyma, 9 cases showed low $\beta 4$ expression and 21 cases showed high expression (Figure 4, A, C and F). It indicates that regardless of the $\beta 4$ expression status in the tumor parenchyma, once the tumor cells enter the circulatory system, the $\beta 4$ expression will be upregulated or maintained at a high level. This phenomenon has not been reported before, and suggests that $\beta 4$ might exert a control on the detached tumor cells through the alteration in expression level.

\section{The expression of $\beta 4$ in PTC cell lines and the knockdown efficiency of $\boldsymbol{\beta}$ 4-shRNA}

We examined $\beta 4$ protein expression in PTC cell lines, including TPC1, K1, BCPAP and the immortalized normal thyroid follicular epithelial cell line Nthy-ori 3-1, by Western blot analyses. The results indicated that its expression was detected only in $\mathrm{K} 1$ cells (Figure $5 \mathrm{~A}$ ). Thus, we chose $\mathrm{K} 1$ as the cell model and decreased its endogenous $\beta 4$ expression by shRNA interference. The knockdown efficiency was approximately $80 \%$ as shown in Figure 5B.

\section{The knockdown of $\beta 4$ inhibited $K 1$ cells' migration, invasion, and motility}

The potential role of $\beta 4$ on K1 cell's migration, invasion, and motility was further explored. As demonstrated in Figure 6A, the number of migrated K1 cells was significantly reduced after transfected with shRNA- $\beta 4 \quad(P<0.001)$, compared with that of shRNA-scramble group. In addition, knockdown of $\beta 4$ drastically inhibited K1 cell's invasion $(P<0.001)$ (Figure 6B). Moreover, although the wound closure rate presented no obvious change at $24 \mathrm{~h}(P=0.136)$, it was significantly reduced at $48 \mathrm{~h}(P=0.003)$ in the shRNA- $\beta 4$ group (Figure 7 ). These results indicated that $\beta 4$ inactivation could suppress K1 cells' mobility.

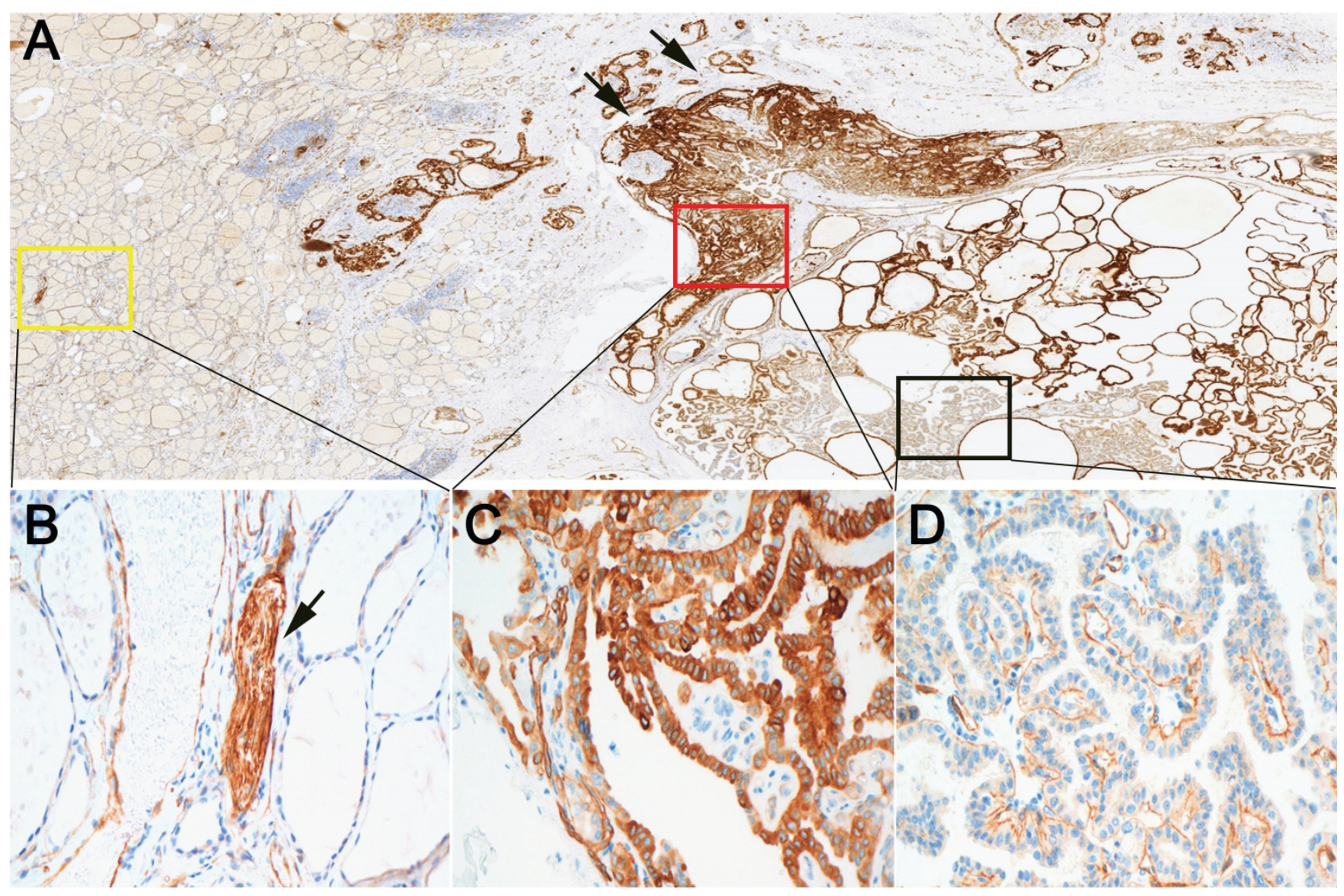

Figure 2. Expression of integrin $\beta 4$ in papillary thyroid carcinoma (PTC) and surrounding noncancerous thyroid tissue by immunohistochemistry. A: At low power, $\beta 4$ demonstrated positive immunoreactions with tumor cells of PTC. The staining intensity was heterogeneous inside the tumor and enhanced at the invasive frontier (arrow). B: The high power field view of yellow square marked in A. $\beta 4$ exhibited negative or faint cytoplasmic staining in noncancerous follicular epithelia. In contrast, $\beta 4$ was strongly expressed by the peripheral nerves (arrow). C: The high power field view of red square marked in $\mathbf{A}$. Tumor cells in this area demonstrated equal or stronger cytoplasmic

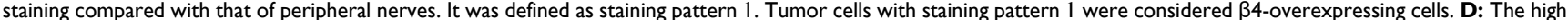
power field view of black square marked in $\mathbf{A}$. Tumor cells in this area demonstrated predominant basal membranous staining with little or no cytoplasmic staining. It was defined as staining pattern 2 . Immunohistochemical stain (A-D). Original magnification: $\times 7(A) ; \times 400(B-D)$. 


\section{The knockdown of $\beta 4$ reduced anchorage-independent growth and promoted anoikis}

Since anchorage-independent growth and resistance to anoikis are necessary for the distant spread of tumor cells $[2,39]$, the impact of $\beta 4$ knockdown on those features was further tested. As shown in Figure 8A, K1 cells treated with shRNA- $\beta 4$ formed fewer colonies than the control cells $(P<0.001)$. In addition, they were more susceptible to anoikis in comparison with the control cells $(P<0.001)$ (Figure $8 \mathrm{~B})$. The above data proved that increased expression of $\beta 4$ could promote the neoplastic cells' survival and antagonize their apoptosis in PTC under the loss-of-adhesion condition.

\section{Metabolic and transductional pathways associated with high $\beta 4$ expression}

To evaluate the potential mechanisms by which $\beta 4$ promotes PTC invasion and metastasis, we stratified PTC cases in TCGA cohort into $\beta 4$ low and high expression groups according to the median value of $\beta 4$ expression level, and explored the enriched pathways correlated with the high $\beta 4$ expression. The GSEA analysis showed that there were 43 significantly upregulated KEGG pathways (Figure
9A), including cell adhesion molecules (CAMs), cytokine-cytokine receptor interactions and regulation of actin cytoskeleton. Those pathways were mainly involved in the regulation of cell-to-cell interactions and epithelial cell migration. In the meanwhile, 28 pathways including oxidative phosphorylation, propanoate metabolism, and the citrate cycle, were significantly down regulated (Figure 9B). Those pathways were mainly associated with the regulation of glucose, amino acid and fatty acid metabolism.

To elucidate the interactions among these pathways, we selected 45 of 71 significant pathways, which were generally related to cell motivation, metabolism and signal transduction in malignancies, for Path-Net analysis. The results demonstrated that there were 39 pathways with a Degree $\geq 1$ (Figure 10 and Supplementary Table S3). The MAPK pathway and propanoate metabolism were located in the network center among the upregulated and downregulated pathways, respectively. So the $\beta 4$-associated increased invasiveness in PTC was more likely to be mediated by the comprehensive regulation on those pathways, specially centered on the nodes of MAPK pathway and propanoate metabolism.
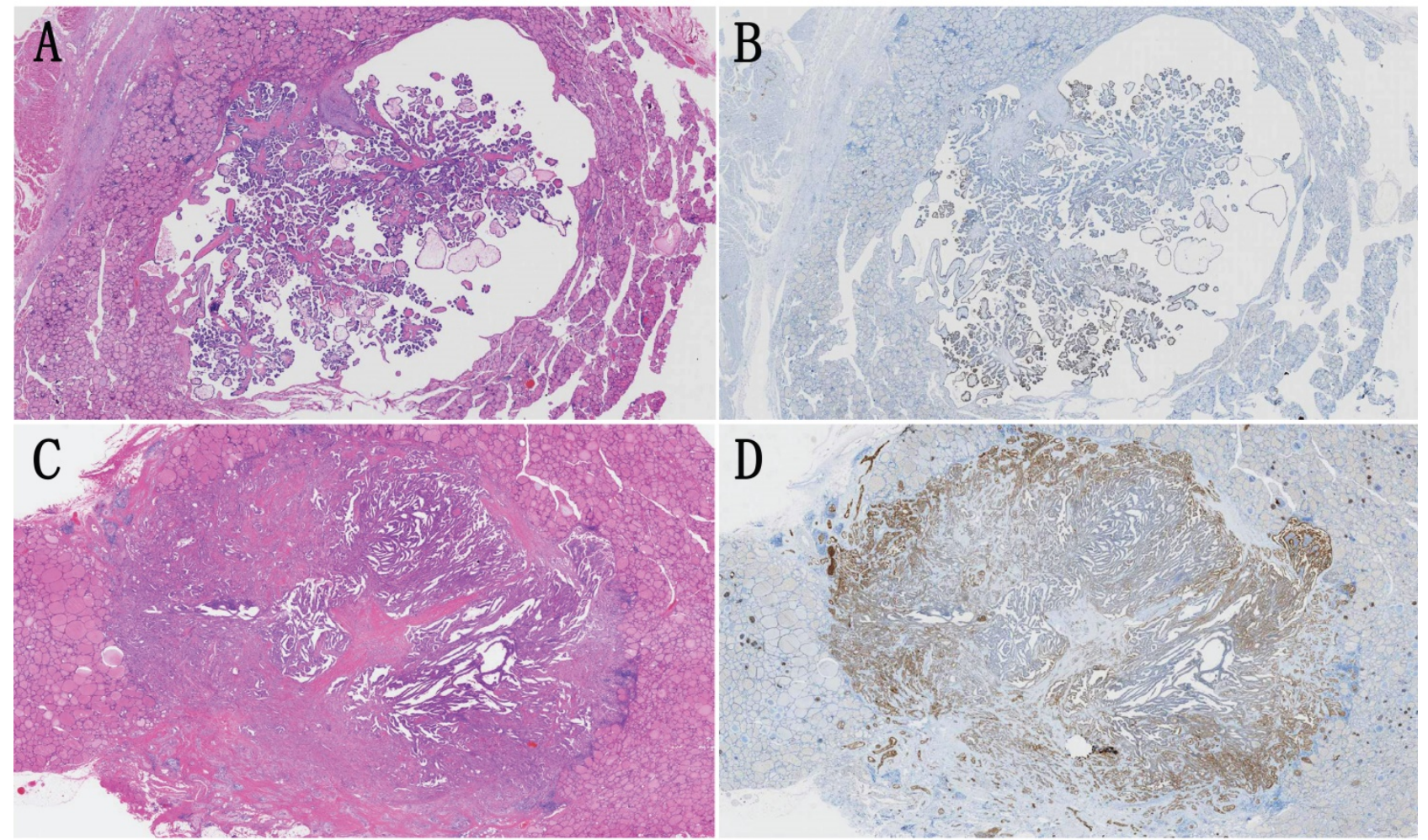

Figure 3. A and B: A representative case of papillary thyroid carcinoma (PTC) with well circumscribed growth pattern (WC-PTC), which was demarcated from surrounding noncancerous thyroid tissues by a thin capsule. The immunostaining of $\beta 4$ was classified as low expression. C and D: A representative case of PTC with poorly circumscribed growth pattern (PC-PTC), which had an infiltrating border. The immunostaining of $\beta 4$ was classified as high expression, and its expression was enhanced at the invasive frontier. Hematoxylin and eosin stain (A and C). Immunohistochemical stain (B and D). Original magnification: $\times 7$ (A-D). 


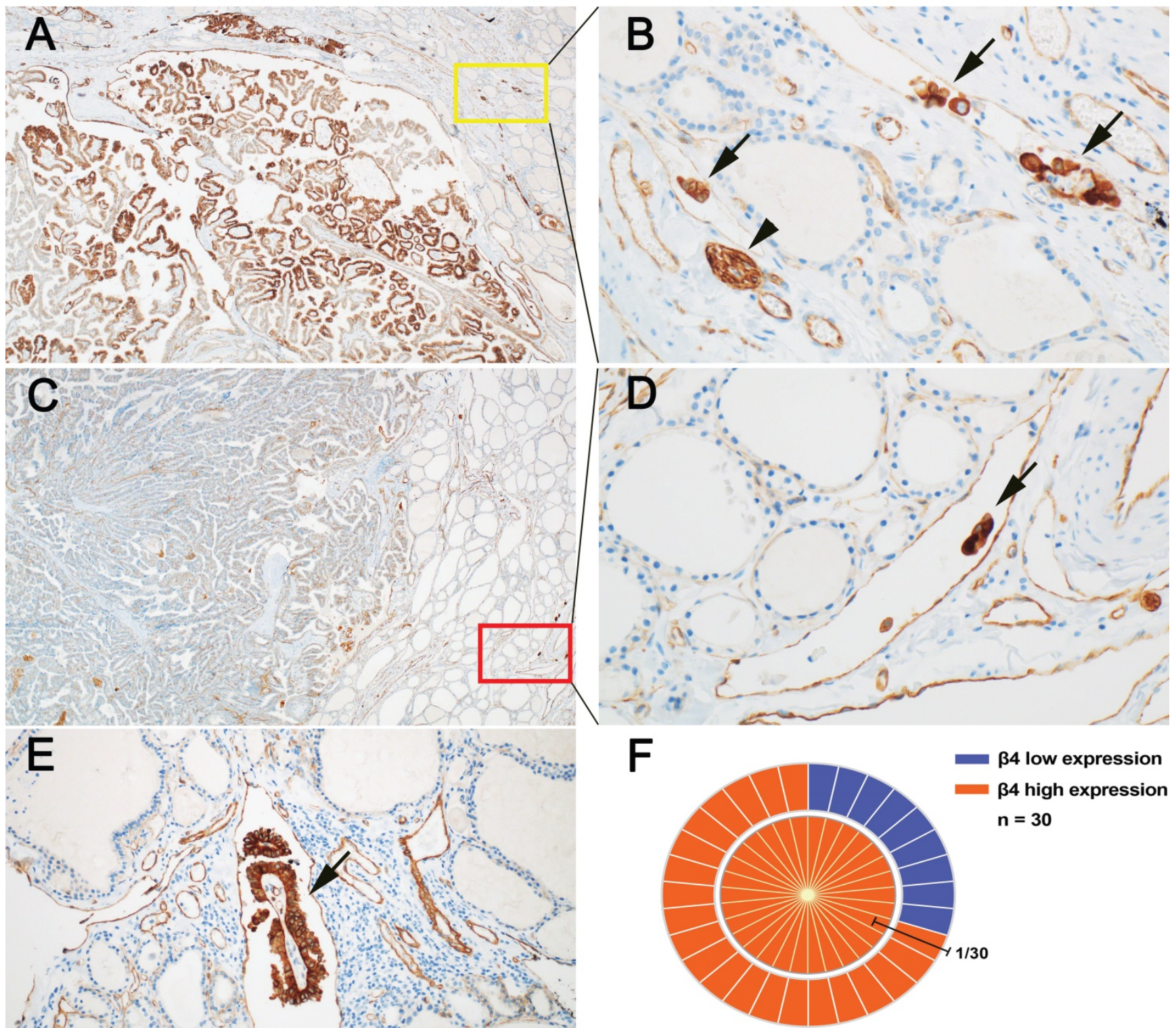

Internal circle: lymphovascular tumor thrombus Outer circle: tumor parenchyma

Figure 4. Expressional features of integrin $\beta 4$ in papillary thyroid carcinoma (PTC) with lymphovascular tumor thrombus (LVT). A and B: In a representative case of PTC, the tumor parenchyma showed high expression of $\beta 4$ (A), and the corresponding LVT (B) in yellow square, also demonstrated high expression of $\beta 4$ (arrow). The expression intensity of LVT was approximately equal to that of peripheral nerves (arrowhead). C and D: In another case of PTC, the tumor parenchyma showed low expression of $\beta 4$ (C), while the corresponding LVT (D) in red square, exhibited high expression of $\beta 4$ (arrow). E: $\beta 4$ was highly expressed in a focus of LVT with fibrovascular stroma (arrow). F: The schematic chart demonstrated the correlation of $\beta 4$ expression between tumor parenchyma and intratumroal LVT. The outer circle represented the expression of $\beta 4$ in the tumor parenchyma, of which 9 cases showed low expression (blue) and 21 cases exhibited high expression (red). The inner circle represented the expression of $\beta 4$ in LVT. Notably, $\beta 4$ was highly expressed in all the LVT. Immunohistochemical stain (A, B, C, D, and E). Original magnification: $\times 40$ (A and C); × 200 (B and D); × 100 (E).

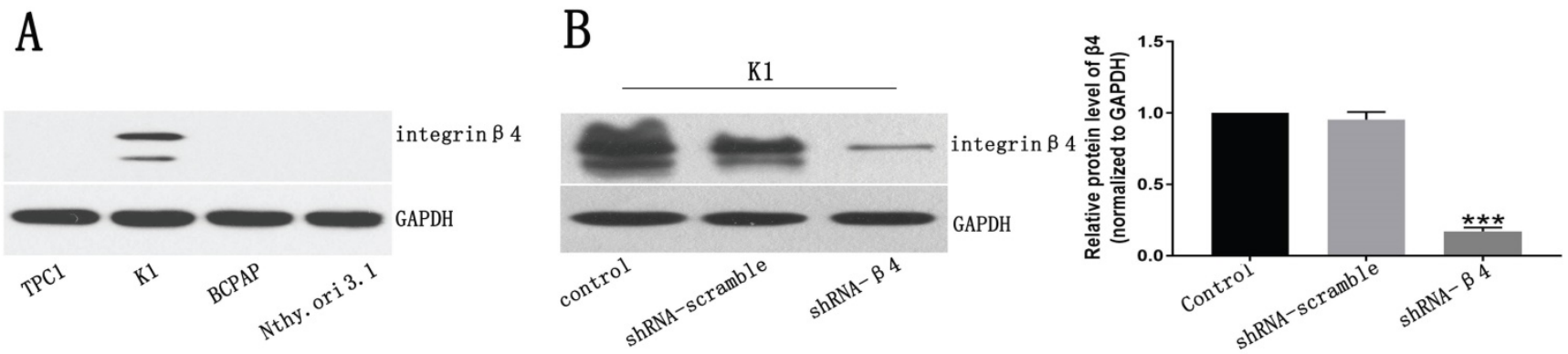

Figure 5. A: Western blot analysis for $\beta 4$ protein expression in papillary thyroid carcinoma cell lines TPC1, K1, BCPAP and the human primary thyroid epithelial cell line Nthy-ori 3-1. $\beta 4$ protein was detected only in K1 cells. B: The $\beta 4$ expression in K1 cells was significantly reduced by shRNA- $\beta 4$ treatment and the knockdown efficiency was around $80 \%$ compared with that of the control and shRNA-scramble groups. Data are expressed as the mean \pm SEM, $n=3(B)$. $* * * P<0.001$ versus the control and shRNA-scramble groups. 
A
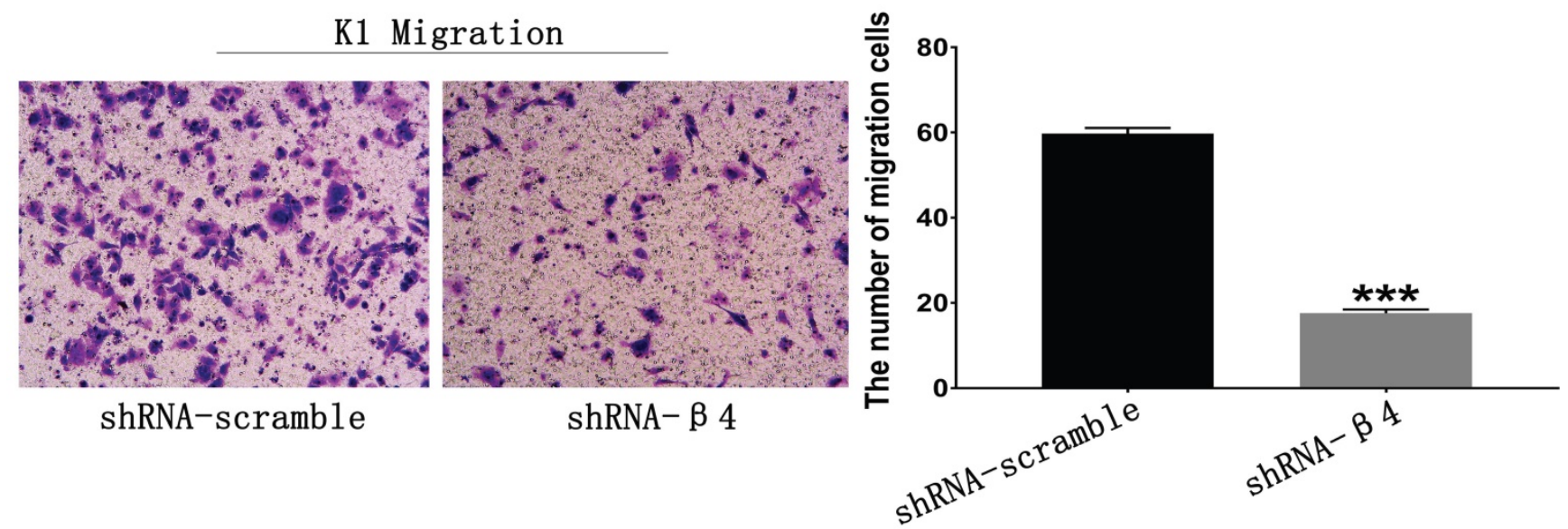

B

K1 Invasion

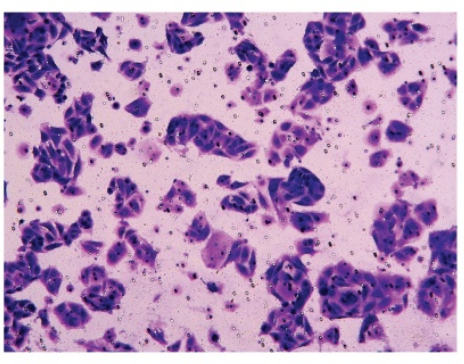

shRNA-scramble

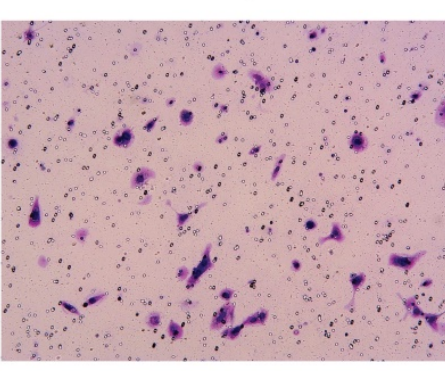

shRNA- $\beta 4$
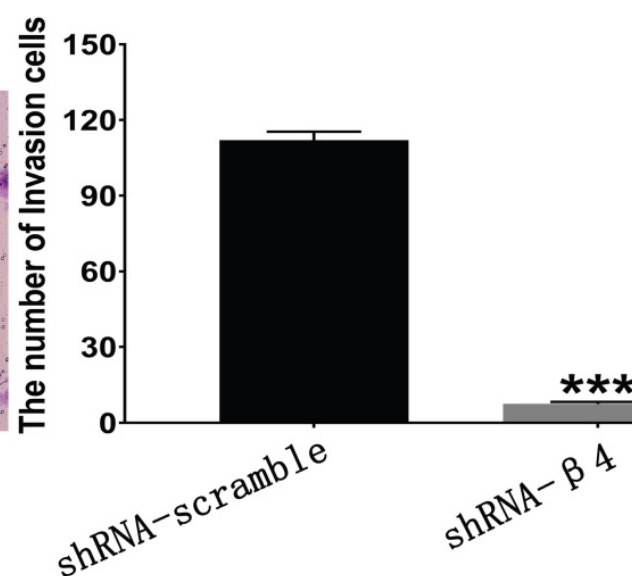

Figure 6. A: Transwell migration assay. The number of migrating $\mathrm{K} 1$ cells was significantly reduced after treatment with shRNA- $\beta 4$ compared with that of the shRNA-scramble group. B: Transwell invasion assay. The number of invasive K1 cells was significantly reduced in cells treated with shRNA- $\beta 4$ compared to the shRNA-scramble cells. Data are expressed as the mean \pm SEM $(A$ and $B), n=3$ (A and $B)$. *** $P<0.001$ versus shRNA-scramble.

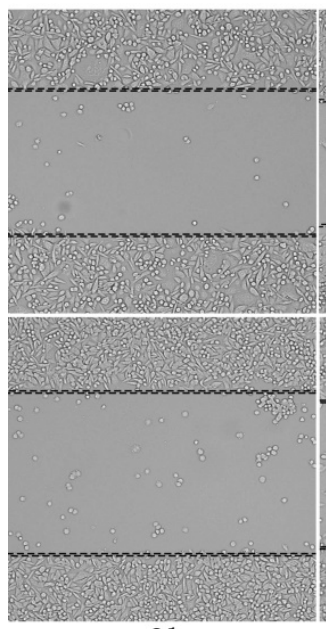

$\mathrm{Oh}$

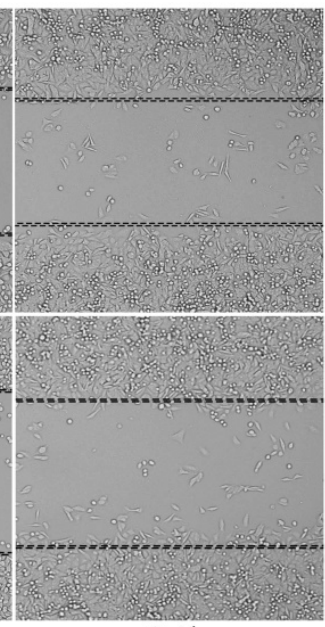

$24 \mathrm{~h}$
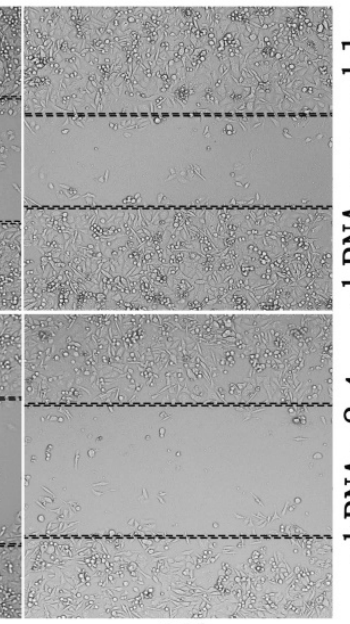

$48 \mathrm{~h}$

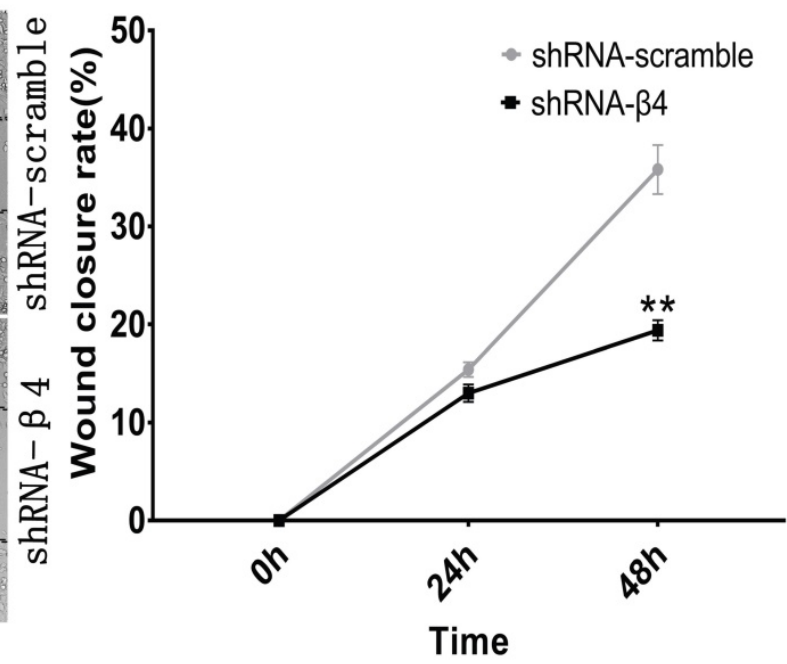

Figure 7. Wound healing assay. Photomicrographs were taken at the zero time point, $24 \mathrm{~h}$, and $48 \mathrm{~h}$ to measure the ratio of the migrating distance relative to the initial wound distance. Wound closure significantly decreased at $48 \mathrm{~h}$ after treatment with shRNA- $\beta 4$. Data are expressed as the mean \pm SEM. $n=3$. $* * P=0.003$ versus shRNA-scramble.

\section{Discussion}

Integrin $\beta 4$ has been shown to promote the aggressiveness in some malignancies, such as invasive breast cancer and squamous cell carcinoma [14, 15, 17]; however, its function in PTC has not been fully explored. Using the large cohort from TCGA, we 
demonstrated here that the $\beta 4$ expression was significantly up-regulated in PTC compared with normal thyroid tissues. The high $\beta 4$ expression was correlated with extensive extrathyroid extension, lymph node metastasis, high TNM stage, and compromised overall survival. These results overall indicated that increased $\beta 4$ expression could boost the tumor's malignant progression.

Next, we explored the effect of $\beta 4$ on the tumor's invasive process. The growth pattern of PTC has been reported to be associated with the tumor's invasiveness [22, 24, 27]. WC-PTC has a low risk for thyroidal capsule invasion compared with that of PC-PTC [23]. We found that $\beta 4$ expression was significantly upregulated in PC-PTC, and the results strengthened the links between the high $\beta 4$ expression and the increased invasive behavior in PTC. Moreover, through reducing the expression of $\beta 4$ by RNA interference in vitro, we showed that the migration, invasiveness, and scratch repair ability of tumor cells were significantly reduced. Those in vitro data directly affirmed that $\beta 4$ could promote the tumor's invasion, and further substantiate the findings from the TCGA and histological analyses.

Then, we explored the effect of $\beta 4$ on the tumor's metastatic process. The presence of LVI has been considered a predictor for metastatic events [37, 38, 40]. We demonstrated that in the high $\beta 4$ expression group, the detection rate of LVI was significantly increased. Since $\beta 4$ could enhance the tumor cells' invasiveness as shown above, it is reasonable to deduce that in high $\beta 4$ expression group, more tumor cells infiltrate into the lymphatic and blood vessels, and thus lead to the increased incidence of LVI. Similarly, elevated $\beta 4$ expression in non-small cell lung cancer has been reported to be associated with more venous invasion [41]. In addition, $\beta 4$ has been suggested to stimulate tumor cells' secretion for vascular endothelial growth factor $[42,43]$ and elicit increased angiogenesis [44], which further create a suitable milieu for the occurrence of LVI.
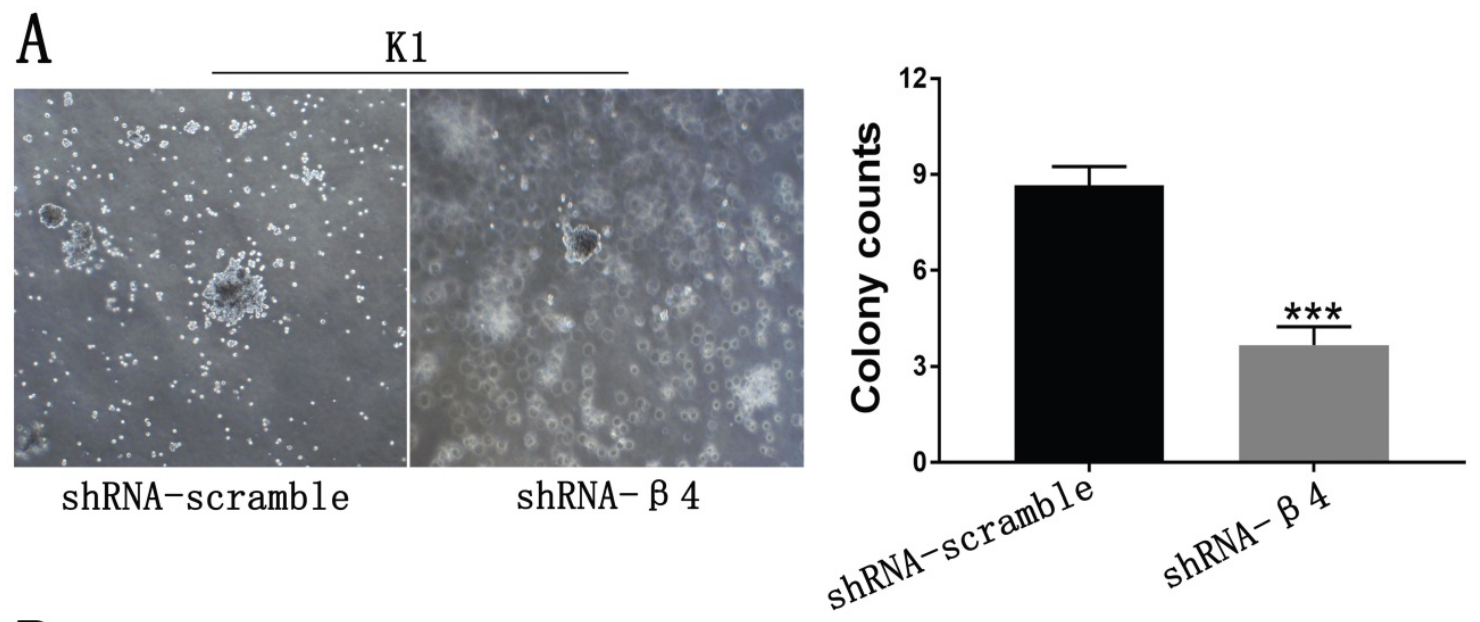

B

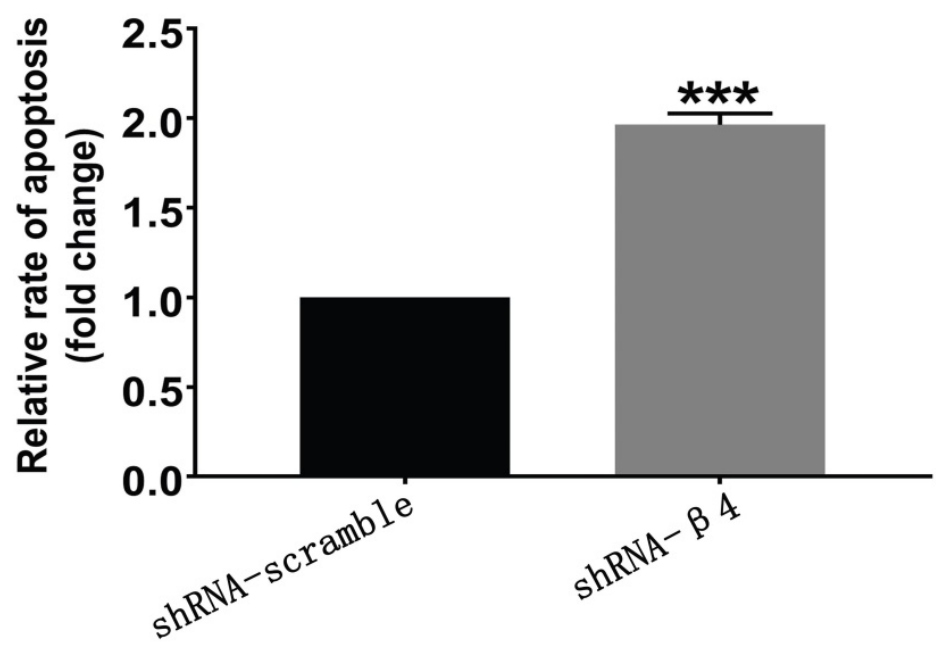

Figure 8. A: Soft agar assay. Representative bright-field images of colonies were captured. The shRNA- $\beta 4$ group formed fewer colonies than the shRNA-scramble group. B: Anoikis analysis. Cell death was assessed by measuring cytoplasmic DNA fragmentation by ELISA. The rate of apoptosis was presented as the fold change of the absorbance (measured at $450 \mathrm{~nm}$ ) of shRNA- $\beta 4$ to shRNA-scramble-treated cells. Data are expressed as the mean \pm SEM $(A$ and $B)$. $n=3(A$ and $B)$. $* * * P<0.001$ versus shRNA-scramble. 

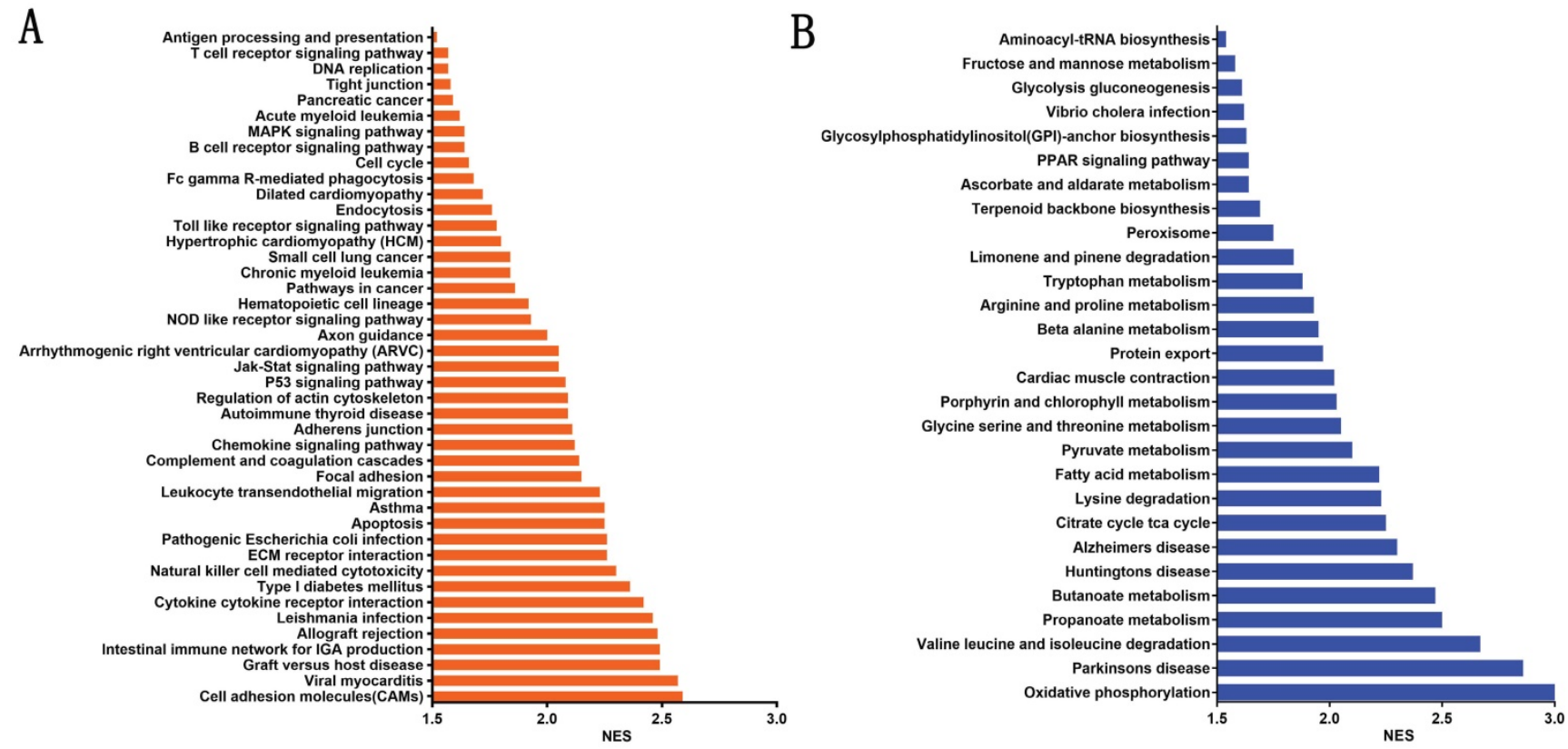

Figure 9. The significantly enriched metabolic and signaling pathways associated with high $\beta 4$ expression in TCGA cohort. The enriched KEGG pathways were clustered by gene set enrichment analysis (GSEA). A false discovery rate (FDR) $<0.05$ was set to designate statistically significant enrichment, and the enriched pathways were sorted by the normalized enrichment score (NES). There were 43 significantly upregulated pathways (A) and 28 significantly downregulated pathways (B).

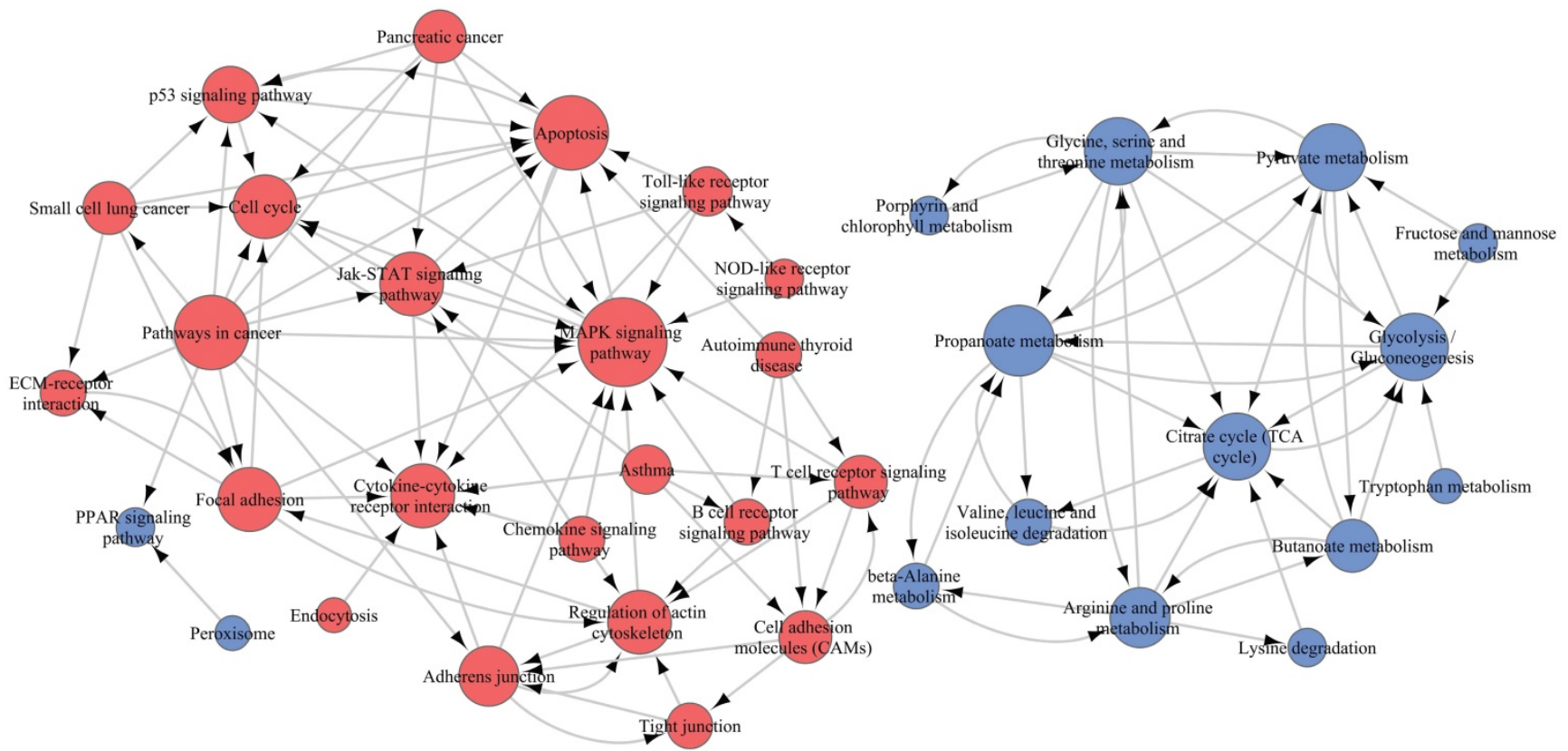

Figure 10. Pathway relation network (Path-Net) analysis. Forty-five significant pathways were chosen to build the Path-Net, and their interactions were evaluated by the value of Degree. As shown in the figure, there were 39 pathways with Degree $\geq 1$. Red dots represented significantly upregulated pathways, blue dots represented significantly downregulated pathways, and lines represented pathway's interactions. The diameter of the dots was positively correlated with the value of Degree.

Circulating tumor thrombus, which is detached from the ECM, must overcome the effect of anoikis to achieve distant metastasis $[45,46]$. Our in vitro results demonstrated that $\beta 4$ could enhance the tumor cells' anoikis resistance and anchorage-independent growth. Interestingly, we also observed that $\beta 4$ was highly expressed in all tumor thrombi in vivo, which had no relations with the expression status in their corresponding tumor parenchyma. These findings suggest that the significance of high $\beta 4$ expression in circulating tumor thrombi in vivo is to promote their survival under the anchorage-independent condition, and thus facilitate the occurrence of metastasis. Although the role of $\beta 4$ in antagonizing anoikis has been recorded in breast cancer and liver cancer, these studies were all based on in vitro data [31, 47, 48]. Our results for the first time provide the definite histological evidence on this process.

Considering some histological variants of PTC are associated with an aggressive phenotype [49-51], 
we further explored the correlations between histological variants of PTC and $\beta 4$ expression status. Because WC-PTCs have distinctive clinicopathological features $[22,24,27]$ and significantly decreased expression of $\beta 4$ in comparison with PC-PTCs, we did not mix the 25 cases of WC-PTC (all of them belonging to the classical variant of PTC) with PC-PTC together during this process. So the histological variant analysis was established specifically on the cases of PC-PTC. The results showed there was no links between $\beta 4$ expression and PTC variants. In addition, $\beta 4$ expression was not associated with the BRAFV600E mutant. We noted that $\beta 4$ was generally highly expressed in the "hotspots" regions, such as the invasive fronts and intravascular tumor thrombi, while frequently expressed at low levels in the "quiescent" areas, such as the tumor's central region and metastatic tumor inside the lymph node parenchyma (data not shown). Thus, $\beta 4$ expression in PTC is more likely dynamically altered to adapt to the tumor's progression rather than fixedly linked to an indicated genetic or histological variant.

To unravel the underlining mechanisms by which $\beta 4$ promotes the tumor's aggressiveness, we performed the GSEA analysis and found that approximately 70 metabolic and signaling pathways were significantly dysregulated in the high $\beta 4$ expression group. Among those upregulated pathways, the MAPK pathway was located in the network center. It has been proved that MAPK pathway plays a pivotal role in modulating the $\beta 4$-dependent invasion and metastasis in invasive breast cancer and squamous cell carcinoma [15, 16, 52]. In addition, the activated cell adhesion molecules (CAMs) and cytokine-cytokine receptor interaction pathways in PTC has been reported to boost lymph node metastasis [53]. On the other hand, the majority of downregulated pathways are involved in the metabolic reprogramming process [2, 54]. The attenuated glucose oxidative phosphorylation pathway has been shown to be a characteristic metabolic feature of PTC and is associated with the tumor's increased lymph node metastasis and high mortality $[53,55]$. Although most of those pathways need to be verified experimentally, the bioinformatics analysis provided a panoramic view of the regulation mechanism of $\beta 4$.

Collectively, our study revealed that integrin $\beta 4$ could promote invasion and antagonize anoikis of PTC, which are intrinsically linked to its upregulated expression in lymphovascular tumor thrombus and tumors with infiltrating growth pattern. Integrin $\beta 4$ could be used as a predictive marker and a therapeutic target for highly aggressive PTC. Further studies will help clarify the interactions among the $\beta 4$-associated pathways identified through the bioinformatics analysis.

\section{Supplementary Material}

Supplementary figures and tables. http://www.jcancer.org/v10p6635s1.pdf

\section{Acknowledgments}

We thank Dr. Xiaoxin Shi for the supports in tissue specimens retrieve, and Dr. Taili $\mathrm{Li}$ and Hengyu Liu for expert technical assistance. We appreciate Jiaxing Zhai (Shanghai Sinotech Genomic Co., Ltd) for assistance in bioinformatics analysis.

\section{Funding Statement}

The study was supported by grants from Shenzhen Health System Research Project (No. SZFZ2018074, Jian Li), Research Foundation of Peking University Shenzhen Hospital (No. JCYJ2018001, Jian Li) and Open Research Fund of State Key Laboratory of Chemical Oncogenomics in 2018 (Jian Li), "San-ming" Project of Medicine in Shenzhen (NO.SZSM20182088, Weihua Yin; NO. SZSM201612041, Xueling Kang).

\section{Competing Interests}

The authors have declared that no competing interest exists.

\section{References}

1. Lambert AW, Pattabiraman DR, Weinberg RA. Emerging Biological Principles of Metastasis. Cell. 2017; 168: 670-91.

2. Hanahan D, Weinberg RA. Hallmarks of cancer: the next generation. Cell. 2011; 144: 646-74.

3. Te Boekhorst V, Friedl P. Plasticity of Cancer Cell Invasion-Mechanisms and Implications for Therapy. Advances in cancer research. 2016; 132: 209-64.

4. Gandalovicova A, Rosel D, Fernandes M, Vesely P, Heneberg P, Cermak V, et al. Migrastatics-Anti-metastatic and Anti-invasion Drugs: Promises and Challenges. Trends Cancer. 2017; 3: 391-406.

5. Ferrari SM, Fallahi P, Politti U, Materazzi G, Baldini E, Ulisse S, et al. Molecular Targeted Therapies of Aggressive Thyroid Cancer. Frontiers in endocrinology. 2015; 6: 176-85.

6. Perros P, Boelaert K, Colley S, Evans C, Evans RM, Gerrard Ba G, et al. Guidelines for the management of thyroid cancer. Clin Endocrinol (Oxf). 2014; 81 Suppl 1: 1-122.

7. Sipos JA, Mazzaferri EL. Thyroid cancer epidemiology and prognostic variables. Clinical oncology (Royal College of Radiologists (Great Britain)). 2010; 22: 395-404.

8. Guo Z, Ge M, Chu YH, Asioli S, Lloyd RV. Recent Advances in the Classification of Low-grade Papillary-like Thyroid Neoplasms and Aggressive Papillary Thyroid Carcinomas: Evolution of Diagnostic Criteria. Advances in anatomic pathology. 2018; 25: 263-72.

9. Cheng $\mathrm{Q}, \mathrm{Li}$ X, Acharya CR, Hyslop T, Sosa JA. A novel integrative risk index of papillary thyroid cancer progression combining genomic alterations and clinical factors. Oncotarget. 2017; 8: 16690-703.

10. Mercurio AM, Rabinovitz I, Shaw LM. The alpha 6 beta 4 integrin and epithelial cell migration. Current opinion in cell biology. 2001; 13: 541-5.

11. Kumar CC. Signaling by integrin receptors. Oncogene. 1998; 17: 1365-73.

12. Mercurio AM, Rabinovitz I. Towards a mechanistic understanding of tumor invasion--lessons from the alphabbeta 4 integrin. Seminars in cancer biology. 2001; 11: 129-41.

13. Lipscomb EA, Mercurio AM. Mobilization and activation of a signaling competent alpha6beta4integrin underlies its contribution to carcinoma progression. Cancer metastasis reviews. 2005; 24: 413-23.

14. Shaw LM, Rabinovitz I, Wang HH, Toker A, Mercurio AM. Activation of phosphoinositide $3-\mathrm{OH}$ kinase by the alpha6beta4 integrin promotes carcinoma invasion. Cell. 1997; 91: 949-60. 
15. Nikolopoulos SN, Blaikie P, Yoshioka T, Guo W, Puri C, Tacchetti C, et al. Targeted deletion of the integrin beta4 signaling domain suppresses laminin-5-dependent nuclear entry of mitogen-activated protein kinases and NF-kappaB, causing defects in epidermal growth and migration. Molecular and cellular biology. 2005; 25: 6090-102.

16. Yoon SO, Shin S, Lipscomb EA. A novel mechanism for integrin-mediated ras activation in breast carcinoma cells: the alpha6beta4 integrin regulates ErbB2 translation and transactivates epidermal growth factor receptor/ErbB2 signaling. Cancer research. 2006; 66: 2732-9.

17. Nistico P, Di Modugno F, Spada S, Bissell MJ. beta1 and beta4 integrins: from breast development to clinical practice. Breast cancer research : BCR. 2014; 16: $459-67$.

18. Liu SY, Ge D, Chen LN, Zhao J, Su L, Zhang SL, et al. A small molecule induces integrin beta4 nuclear translocation and apoptosis selectively in cancer cells with high expression of integrin beta4. Oncotarget. 2016; 7: $16282-96$

19. Giancotti FG. Targeting integrin beta 4 for cancer and anti-angiogenic therapy. Trends in pharmacological sciences. 2007; 28: 506-11.

20. Serini G, Trusolino L, Saggiorato E, Cremona O, De Rossi M, Angeli A, et al. Changes in integrin and E-cadherin expression in neoplastic versus normal thyroid tissue. J Natl Cancer Inst. 1996; 88: 442-9.

21. Kitajiri S, Hosaka N, Hiraumi H, Hirose T, Ikehara S. Increased expression of integrin beta- 4 in papillary thyroid carcinoma with gross lymph node metastasis. Pathol Int. 2002; 52: 438-41.

22. Rivera M, Tuttle RM, Patel S, Shaha A, Shah JP, Ghossein RA. Encapsulated papillary thyroid carcinoma: a clinico-pathologic study of 106 cases with emphasis on its morphologic subtypes (histologic growth pattern). Thyroid : official journal of the American Thyroid Association. 2009; 19: 119-27.

23. Eloy C, Santos J, Soares P, Sobrinho-Simoes M. The preeminence of growth pattern and invasiveness and the limited influence of BRAF and RAS mutations in the occurrence of papillary thyroid carcinoma lymph node metastases. Virchows Archiv : an international journal of pathology. 2011; 459: 265-76.

24. Pisanu A, Deplano D, Reccia I, Porceddu G, Uccheddu A. Encapsulated papillary thyroid carcinoma: is it a distinctive clinical entity with low-grade malignancy? J Endocrinol Invest. 2013; 36: 78-83.

25. Hung YP, Barletta JA. A user's guide to non-invasive follicular thyroid neoplasm with papillary-like nuclear features (NIFTP). Histopathology. 2018; 72: 53-69.

26. Xu B, Tallini G, Ghossein RA. Noninvasive Follicular Thyroid Neoplasm with Papillary-Like Nuclear Features: Historical Context, Diagnosis, and Future Challenges. Endocrine pathology. 2017; 28: 128-38.

27. Rosai J, Fajin JA, Piana S, et al. Papillary thyroid carcinoma. In: Lioyd RV, ed. WHO Classification of Tumours of Endocrine Organs, 4th ed. Lyon: International Agency for Research on Cancer; 2017: 81-91.

28. Masugi Y, Yamazaki K, Emoto K, Effendi K, Tsujikawa H, Kitago M, et al. Upregulation of integrin beta4 promotes epithelial-mesenchymal transition and is a novel prognostic marker in pancreatic ductal adenocarcinoma. Laboratory investigation; a journal of technical methods and pathology. 2015; 95: 308-19.

29. Qiu T, Lu H, Guo L, Huang W, Ling Y, Shan L, et al. Detection of BRAF mutation in Chinese tumor patients using a highly sensitive antibody immunohistochemistry assay. Scientific reports. 2015; 5: 9211-14.

30. Li Y, Li Z, Zhang C, Li P, Wu Y, Wang C, et al. Cardiac Fibroblast-Specific Activating Transcription Factor 3 Protects Against Heart Failure by Suppressing MAP2K3-p38 Signaling. Circulation. 2017; 135: 2041-57.

31. Leng C, Zhang ZG, Chen WX, Luo HP, Song J, Dong W, et al. An integrin beta4-EGFR unit promotes hepatocellular carcinoma lung metastases by enhancing anchorage independence through activation of FAK-AKT pathway. Cancer letters. 2016; 376: 188-96.

32. Zielske SP, Stevenson M. Importin 7 may be dispensable for human immunodeficiency virus type 1 and simian immunodeficiency virus infection of primary macrophages. Journal of virology. 2005; 79: 11541-6.

33. Yi M, Horton JD, Cohen JC, Hobbs HH, Stephens RM. WholePathwayScope: a comprehensive pathway-based analysis tool for high-throughput data. BMC bioinformatics. 2006; 7: 30-53

34. Wang F, Hu S, Liu W, Qiao Z, Gao Y, Bu Z. Deep-sequencing analysis of the mouse transcriptome response to infection with Brucella melitensis strains of differing virulence. PloS one. 2011; 6: e28485-96.

35. Vuong HG, Altibi AMA, Duong UNP, Hassell L. Prognostic implication of BRAF and TERT promoter mutation combination in papillary thyroid carcinoma-A meta-analysis. Clin Endocrinol (Oxf). 2017; 87: 411-7.

36. Nasirden A, Saito T, Fukumura Y, Hara K, Akaike K, Kurisaki-Arakawa A, et al. In Japanese patients with papillary thyroid carcinoma, TERT promoter mutation is associated with poor prognosis, in contrast to BRAF (V600E) mutation. Virchows Archiv : an international journal of pathology. 2016; 469: 687-96.

37. Lang BH, Shek TW, Wan KY. The significance of unrecognized histological high-risk features on response to therapy in papillary thyroid carcinoma measuring 1-4 cm: implications for completion thyroidectomy following lobectomy. Clin Endocrinol (Oxf). 2017; 86: 236-42.

38. Pontius LN, Youngwirth LM, Thomas SM, Scheri RP, Roman SA, Sosa JA. Lymphovascular invasion is associated with survival for papillary thyroid cancer. Endocr Relat Cancer. 2016; 23: 555-62.
39. Paoli P, Giannoni E, Chiarugi P. Anoikis molecular pathways and its role in cancer progression. Biochimica et biophysica acta. 2013; 1833: 3481-98.

40. Sezer A, Celik M, Yilmaz Bulbul B, Can N, Tastekin E, Ayturk S, et al. Relationship between lymphovascular invasion and clinicopathological features of papillary thyroid carcinoma. Bosn J Basic Med Sci. 2017; 17: 144-51.

41. Stewart RL, West D, Wang C, Weiss HL, Gal T, Durbin EB, et al. Elevated integrin alpha6beta4 expression is associated with venous invasion and decreased overall survival in non-small cell lung cancer. Human pathology. 2016; $54:$ 174-83

42. Chung J, Bachelder RE, Lipscomb EA, Shaw LM, Mercurio AM. Integrin (alpha 6 beta 4) regulation of eIF-4E activity and VEGF translation: a survival mechanism for carcinoma cells. The Journal of cell biology. 2002; 158: 165-74.

43. Fan J, Cai B, Zeng M, Hao Y, Giancotti FG, Fu BM. Integrin beta4 signaling promotes mammary tumor cell adhesion to brain microvascular endothelium by inducing ErbB2-mediated secretion of VEGF. Annals of biomedical engineering. 2011; 39: 2223-41.

44. Hanahan D, Folkman J. Patterns and emerging mechanisms of the angiogenic switch during tumorigenesis. Cell. 1996; 86: 353-64.

45. Micalizzi DS, Maheswaran S, Haber DA. A conduit to metastasis: circulating tumor cell biology. Genes \& development. 2017; 31: 1827-40.

46. Cheung KJ, Ewald AJ. A collective route to metastasis: Seeding by tumor cell clusters. Science (New York, NY). 2016; 352: 167-9.

47. Bon G, Folgiero V, Bossi G, Felicioni L, Marchetti A, Sacchi A, et al. Loss of beta4 integrin subunit reduces the tumorigenicity of MCF7 mammary cells and causes apoptosis upon hormone deprivation. Clinical cancer research : an official journal of the American Association for Cancer Research. 2006; 12: 3280-7.

48. Friedland JC, Lakins JN, Kazanietz MG, Chernoff J, Boettiger D, Weaver VM. alpha6beta4 integrin activates Rac-dependent p21-activated kinase 1 to drive NF-kappaB-dependent resistance to apoptosis in 3D mammary acini. Journal of cell science. 2007; 120: 3700-12.

49. Nath MC, Erickson LA. Aggressive Variants of Papillary Thyroid Carcinoma: Hobnail, Tall Cell, Columnar, and Solid. Advances in anatomic pathology. 2018; 25: 172-9.

50. Vuong HG, Odate T, Duong UNP, Mochizuki K, Nakazawa T, Katoh R, et al. Prognostic importance of solid variant papillary thyroid carcinoma: A systematic review and meta-analysis. Head \& neck. 2018; 40: 1588-97.

51. Pillai S, Gopalan V, Smith RA, Lam AK. Diffuse sclerosing variant of papillary thyroid carcinoma--an update of its clinicopathological features and molecular biology. Critical reviews in oncology/hematology. 2015; 94: 64-73.

52. Dutta U, Shaw LM. A key tyrosine (Y1494) in the beta4 integrin regulates multiple signaling pathways important for tumor development and progression. Cancer research. 2008; 68: 8779-87.

53. Ab Mutalib NS, Othman SN, Mohamad Yusof A, Abdullah Suhaimi SN, Muhammad R, Jamal R. Integrated microRNA, gene expression and transcription factors signature in papillary thyroid cancer with lymph node metastasis. PeerJ. 2016; 4: e2119-41.

54. Coelho RG, Fortunato RS, Carvalho DP. Metabolic Reprogramming in Thyroid Carcinoma. Frontiers in oncology. 2018; 8: 82-96.

55. Nilubol N, Sukchotrat C, Zhang L, He M, Kebebew E. Molecular pathways associated with mortality in papillary thyroid cancer. Surgery. 2011; 150: 1023-31. 